ESASHIKA, DAS; MICHEREFF-FILHO, M; BASTOS, CS; INOUE-NAGATA, AK; DIAS, AM; RIBEIRO, MGPM. 2016. Suscetibilidade de adultos de Bemisia tabaci biótipo B a inseticidas. Horticultura Brasileira 34: 189-195. DOI - http://dx.doi.org/10.1590/S0102-053620160000200007

\title{
Suscetibilidade de adultos de Bemisia tabaci biótipo B a inseticidas
}

\author{
Danilo AS Esashika' ${ }^{1}$; Miguel Michereff-Filho²; Cristina S Bastos ${ }^{1}$; Alice K Inoue-Nagata²; Antônio M \\ Dias $^{1}$; Matheus GPM Ribeiro ${ }^{3}$ \\ 'Universidade de Brasília (UnB), Brasília-DF, Brasil; daniloakio09@hotmail.com; cschetino@unb.br; antoniokaimbe@gmail.com; \\ ${ }^{2}$ Embrapa Hortaliças, Brasília-DF, Brasil; miguel.michereff@embrapa.br; alice.nagata@embrapa.br; ${ }^{3}$ University of Nebraska-Lincoln \\ (UNL), Department of Entomology, Nebraska, USA; matheusgpmr@huskers.unl.edu.
}

\section{RESUMO}

A associação de alguns vírus fitopatogênicos com seus vetores pode ou não alterar a ação do controle químico. Este trabalho objetivou avaliar a suscetibilidade de moscas-brancas virulíferas (com aquisição do begomovírus Tomato severe rugose virus, ToSRV) e avirulíferas (sem aquisição do ToSRV) aos principais inseticidas registrados para o seu controle na cultura do tomateiro. Foram realizados ensaios com plantas de tomateiro e discos foliares de feijão-de-porco. Os tratamentos foram arranjados em esquema fatorial de 7 (seis inseticidas + controle) e de 5 (quatro inseticidas + controle) $\mathrm{x}$ 2 [mosca-branca (MB) virulífera (V) ou avirulífera (AV)] e dispostos no delineamento em blocos ao acaso com seis e 25 repetições para o tomateiro e feijão-de-porco, respectivamente. Os inseticidas e concentrações avaliados foram: a) tomateiro: acefato (100 g), clotianidina $(20 \mathrm{~g})$, pimetrozina $(40 \mathrm{~g})$, piriproxifem $(75 \mathrm{~mL})$ e tiametoxam $(20 \mathrm{~g}$ de i.a./100 L de calda) e diafentiurom ( $800 \mathrm{~g}$ de i.a./300 L de calda); b) feijão-de-porco: acefato $(100 \mathrm{~g})$, tiametoxam $(20 \mathrm{~g})$, pimetrozina (40 g de i.a./100 L) e diafentiurom (800 g de i.a./300 L de calda). Não houve diferença na suscetibilidade do vetor em razão de sua condição (V ou AV). Os inseticidas diafentiurom $(87,68 \% \pm 4,96)$ e tiametoxam $(43,95 \% \pm 9,43)$ proporcionaram maior mortalidade de MB no tomateiro, enquanto no feijão-de-porco diafentiurom $(92,01 \% \pm 2,68)$ e tiametoxam $(86,39 \% \pm 2,74)$ apresentaram desempenho similar. Diafentiurom foi o único inseticida que proporcionou controle satisfatório de B. tabaci em ambos os ensaios avaliados.

Palavras-chave: Solanum lycopersicum, Canavalia ensiformes, controle químico, fitness.

\begin{abstract}
Susceptibility of Bemisia tabaci biotype B to insecticides

The association between some plant pathogenic viruses and their vectors may or may not alter the action of chemical control. This study aimed at evaluating the susceptibility of viruliferous (transmitter of the begomovirus Tomato severe rugose virus, ToSRV) and aviruliferous (non-transmitter of ToSRV) Bemisia tabaci biotype $\mathrm{B}$ to the main insecticides registered to its control in tomato crops. Two sets of experiments were carried out with tomato plants and foliar discs of jack beans. The treatments were schemed in a factorial design of 7 (six insecticides + control) and 5 (four insecticides + control) $\mathrm{x} 2$ [viruliferous (V) or aviruliferous (AV) whiteflies (WF)] and arranged in completely randomized blocks design with six and 25 replications, respectively, for tomato and jack beans. The following insecticides and concentrations were evaluated: a) tomato: acephate (100 g), clothianidin (20 g), pymetrozine $(40 \mathrm{~g})$, pyriproxyfen $(75 \mathrm{~mL})$ and thiametoxan $(20 \mathrm{~g}$ of a.i./100 L), and diafenthiuron $(800 \mathrm{~g}$ of a.i./300 L of solution); b) jack beans: acephate (100 g), thiametoxan (20 g), pymetrozine $(40 \mathrm{~g}$ of a.i./100 L) and diafenthiuron $(800 \mathrm{~g}$ of a.i./300 L). The insecticide susceptibility of whiteflies was not altered by their viruliferous condition (V or AV). The insecticides diafenthiuron $(87.68 \% \pm 4.96)$ and thiametoxam $(43.94 \% \pm 9.43)$ caused the highest mortality of whiteflies in tomatoes. In jack beans, diafenthiuron $(92.01 \% \pm 2.68)$ and thiametoxam $(86,39 \% \pm 2,74)$ caused similar mortality. Among the tested insecticides, diafenthiuron was the only one causing significant mortality of B. tabaci biotype B.
\end{abstract}

Keywords: Solanum lycopersicum, Canavalia ensiformes, chemical control, fitness.

(Recebido para publicação em 21 de julho de 2015; aceito em 14 de janeiro de 2016) (Received on July 21, 2015; accepted on January 14, 2016)

$\mathrm{O}$ tomateiro (Solanum lycopersicum, Solanaceae) é uma das hortaliças mais produzidas na região Centro-Oeste, ocupando a segunda posição em volume produzido no cenário nacional. O Distrito Federal, por sua vez, é o segundo produtor da região Centro-Oeste, ficando atrás apenas de Goiás, reforçando a grande relevância da cultura para o de- senvolvimento da região (IBGE, 2013).

A mosca-branca, Bemisia tabaci (Hemiptera: Aleyrodidae), é uma praga de importância mundial em diversas culturas agrícolas e ornamentais. Já foram descritos pelo menos 41 biótipos da espécie B. tabaci (De Barro et al., 2005), sendo o biótipo B [=Middle East Asia Minor 1 species (MEAM1)] um dos maiores causadores de prejuízos econômicos (Dinsdale et al., 2010). Em tomateiros, o principal problema decorrente do seu ataque é a transmissão de um complexo de begomovírus (pelo menos 16 espécies) capazes de comprometer a produção em até $60 \%$, devido à redução no crescimento da planta doente e, consequentemente, no número de 
frutos por planta (Giordano et al., 2005). Tomato severe rugose virus (ToSRV) é um dos begomovírus predominante no Brasil (Barbosa et al., 2011) sendo transmitido por B. tabaci biótipo B de forma persistente-circulativa (Rubinstein \& Czosnek, 1997).

Segundo Santos et al. (2003), os adultos de $B$. tabaci biótipo B podem adquirir o begomovírus alimentando-se por pelo menos 15 minutos (período de acesso de aquisição, PAA) de uma planta doente, sendo capaz de transmiti-lo após 16 horas (período de latência, PL), tão logo mantenha contato com uma planta sadia por pelo menos 30 minutos de alimentação (período de acesso de inoculação, PAI).

Não há controle curativo para doenças causadas por begomovírus. Portanto, para o seu manejo no tomateiro devem-se empregar medidas preventivas, incluindo o controle do vetor, via aplicação de inseticidas. Vale destacar que devido à magnitude das perdas causadas à produção em decorrência da transmissão do vírus, a detecção de apenas um adulto do inseto por planta desencadeia a adoção de controle químico de $B$. tabaci (Byrne \& Bellows Junior, 1991).

As informações relativas à influência dos begomovírus sobre a biologia de B. tabaci biótipo B destacam que essa associação pode reduzir a longevidade e a fecundidade (Jiu et al., 2007), acelerar o desenvolvimento ninfal (Maluta et al., 2014) e aumentar a fecundidade de fêmeas (McKenzie, 2002) e a longevidade de machos (Maluta et al., 2014) ou não alterar a biologia do inseto (Liu et al., 2009).

Vale destacar ainda que já existem relatos de populações de $B$. tabaci resistentes a praticamente todas as moléculas empregadas para o seu controle, incluindo o piriproxifem (Ma et al., 2010) e o diafentiurom (Shadmany et al., 2014) e inseticidas do grupo dos neonicotinoides (Silva et al., 2009) e organofosforados (Alon et al., 2008). Há relatos ainda de resistência cruzada de $B$. tabaci a neonicotinoides e à pimetrozina (Gorman et al., 2010). Muitos desses estudos atribuem a resistência a alterações nas enzimas citocromo P450 (Gorman et al., 2010; Ma et al., 2010) e glutationa S-transferase (Ma et al., 2010).
Alguns estudos destacam que biótipos de vetores sabidamente mais resistentes aos inseticidas empregados no seu controle, a exemplo do biótipo A de Myzus persicae (Hemiptera: Aphididae), são também mais eficientes na transmissão do Potato leafroll virus (PLRV) (Nikan et al., 2013).

Até o presente momento, não existem relatos de trabalhos que tenham tratado da alteração na suscetibilidade de insetos a inseticidas em virtude de sua condição (associação ou não com vírus fitopatogênicos). Caso a associação entre o ToSRV e B. tabaci possa alterar características biológicas do inseto de tal forma a reduzir a mortalidade causada pelo controle químico, a forma de uso dessa tática de controle deverá ser repensada.

Portanto, este trabalho objetivou avaliar a suscetibilidade de adultos de B. tabaci biótipo B virulíferos (com aquisição do ToSRV) e avirulíferos (sem aquisição do ToSRV) aos principais inseticidas registrados para o seu controle na cultura do tomateiro.

\section{MATERIAL E MÉTODOS}

\section{Local de realização dos ensaios}

$O$ presente trabalho foi realizado no viveiro de mudas da Fazenda Água Limpa pertencente à Universidade de Brasília e no Laboratório de Entomologia da Embrapa Hortaliças, ambos em Brasília-DF, em sala climatizada para temperatura de $25 \pm 1^{\circ} \mathrm{C}$, UR de $50 \%$ e fotofase de 12 horas.

Foram realizados dois ensaios distintos, sendo um com plantas de tomateiro cultivadas em vasos e o outro com discos foliares de feijão-de-porco (Canavalia ensiformis, Fabaceae). Estes ensaios foram concebidos para confirmar a consistência dos resultados obtidos em condições diversificadas (isto é, com plantas de tomateiro cultivadas em vasos e com discos foliares de feijão-de-porco).

\section{Obtenção dos insetos empregados nos ensaios}

Os adultos de B. tabaci utilizados no trabalho foram identificados como pertencentes ao biótipo $B$, após extração de DNA total pelo método CTAB (Doyle \& Doyle, 1983), seguido de PCR com os oligonucleotídeos específicos para o gene citocromo oxidase mitocondrial I (mtCOI), C1-J-2195-FW (5'-TTGATTTTTTGGTCATCCAGAAGT-3') e C1-J-2195-RV (5'-TCCAATGCACTAATCTGCCATATTA-3'), digestão enzimática conforme Frohlich et al. (1999) e sequenciamento direto do produto de PCR. Estes insetos foram provenientes de criação massal empregando como hospedeiro couve brócolis (Brassica oleracea var. italica, cv. Ramoso Santana), que não é suscetível aos begomovírus do tomateiro, cultivada em casa de vegetação revestida com vidro.

Para obtenção dos adultos com idade sincronizada, plantas de brócolis com alta infestação de ninfas de $B$. tabaci no quarto instar e que não continham adultos foram acondicionadas em gaiolas de PVC teladas com voil [90x70x70 $\mathrm{cm}$ (largura $\mathrm{x}$ profundidade $\mathrm{x}$ altura)] por dois dias. Nesse período, todos os adultos emergidos (até $48 \mathrm{~h}$ de idade e sem sexagem prévia), foram transferidos com auxílio de um aspirador manual (preparado com tubo de polietileno, tecido voil e ponteira P1000) para gaiolas teladas contendo plantas de tomateiro ( $S$. lycopersicum, cv. Viradoro) sadias [para obtenção de moscas-brancas avirulíferas $(\mathrm{AV})]$ ou infectadas [para obtenção de moscas-brancas virulíferas (V)] pelo isolado 1164 de ToSRV. Esse isolado foi coletado na região de Goiás, identificado por clonagem do genoma completo dos componentes virais (Inoue-Nagata et al., 2004) e disponibilizado pelo Laboratório de Virologia da Embrapa Hortaliças. Os insetos permaneceram em contato com as plantas por três dias, sendo esse tempo suficiente para a aquisição do vírus pelos adultos de mosca-branca e para que os insetos estivessem aptos a transmitir o vírus, conforme Santos et al. (2003). Para a confirmação da condição dos insetos (se avirulíferos ou virulíferos), antes de serem utilizados nos ensaios, coletaram-se 50 adultos de cada gaiola, sendo o DNA total de cada indivíduo extraído (Doyle \& Doyle, 1987) e usado para PCR com os oligonucleotídeos universais para detecção de geminivírus pALv496 e pARc1978 (Rojas et al., 1993). A am- 
plificação de fragmento específico de 1,1 $\mathrm{kb}$ comprovou a presença do genoma viral em cada inseto.

\section{Ensaio com tomateiro}

As plantas de tomateiro utilizadas no ensaio foram provenientes do cultivo em bandejas de isopor de 96 células, em casas de vegetação recobertas por vidro, sendo, posteriormente, transplantadas para vasos de $5 \mathrm{~L}$ de capacidade, preenchidos com substrato Plantmax $^{\circledR}$, quando apresentavam de 3 a 4 folhas verdadeiras, aos 30 dias após a semeadura. Os vasos foram mantidos no interior de gaiolas de $32 \times 32 \times 100$ $\mathrm{cm}$ (largura $\mathrm{x}$ profundidade $\mathrm{x}$ altura) revestidas com organza, até o momento de utilização no ensaio. A cultivar empregada nos ensaios foi Santa Clara VS 5600 proveniente da Sakata Seeds ${ }^{\circledR}$. O delineamento experimental utilizado foi em blocos casualizados com seis repetições alocadas no tempo e a parcela experimental foi representada por um vaso contendo uma planta de tomateiro. Os tratamentos foram arranjados em esquema fatorial de 7 [seis inseticidas (acefato, clotianidina, diafentiurom, piriproxifem, pimetrozina e tiametoxam) nas concentrações listadas na Tabela 1 e água como testemunha] x 2 (duas condições de mosca-branca: avirulífera [(AV) sem aquisição prévia de ToSRV] e virulífera [(V) com aquisição prévia de ToSRV]. As concentrações dos inseticidas foram determinadas tendo por base a dose recomendada para o controle do inseto no tomateiro e em atenção ao que consta no registro do produto no Ministério da Agricultura, Pecuária e Abastecimento (Brasil, 2012).

As mudas de tomateiro foram pulverizadas com as diferentes soluções aos 21 dias após o transplantio, quando as plantas se encontravam em estádio vegetativo. Para tal, empregou-se um pulverizador manual de jardineiro de compressão prévia (compressão manual, como realizado nos pulverizadores costais), de 1,25 L de capacidade, equipado com bico tipo cone, marca Guarany ${ }^{\circledR}$. As caldas inseticidas foram preparadas empregando-se água disponível no local e não tratada, sendo a quantidade de ingrediente ativo adicionada, ajustada para um volume final de calda de 1,25 $\mathrm{L}$, tendo por base a recomendação apre- sentada na Tabela 1. As caldas assim obtidas foram destinadas ao pulverizador e empregadas na pulverização das plantas.

As plantas recém-pulverizadas foram mantidas em temperatura ambiente até a completa secagem. Em seguida, a terceira folha completamente expandida a partir do ápice das plantas foi infestada com cerca de 50 adultos da mosca-branca de até cinco dias de idade e não sexados, que foram confinados às plantas por intermédio de sacolas de organza de $21 \times 35 \mathrm{~cm}$, tamanho suficiente para acomodar a folha infestada, sendo o modelo adaptado da metodologia de Moreira et al. (2005) que empregaram sacolas de organza de $20 \times 28 \mathrm{~cm}$. As gaiolas foram fixadas às plantas empregando-se um fio de barbante e as plantas foram mantidas em viveiro contendo telhado (abrigadas do sol e da chuva) em uma condição ambiental que variou de $27 \pm 4^{\circ} \mathrm{C}$ e $60 \pm 20 \%$ de temperatura e umidade relativa, respectivamente, durante o período experimental. Decorridas $48 \mathrm{~h}$ da liberação dos insetos, tempo coincidente com a ação esperada para a maioria dos produtos testados, foi procedida a contagem do número de insetos vivos e mortos de mosca-branca e obtida a mortalidade em cada parcela experimental.

Foi utilizada a fórmula de Schenneider-Orelli (Püntener, 1981) para correção da mortalidade dos tratamentos pela respectiva testemunha:

$$
M_{\text {corrigida }}(\%)=\left(\frac{M_{\text {trat }}-M_{\text {test }}}{100-M_{\text {test }}}\right) * 100
$$

onde: $M_{\text {corrigida }}:$ mortalidade no tratamento corrigida pela testemunha $(\%)$; $\mathrm{M}_{\text {trat }}:$ mortalidade no tratamento $(\%)$ $\mathrm{M}_{\text {test. }}$ : mortalidade na testemunha (\%).

Os dados de mortalidade corrigida foram submetidos à análise de variância e, posteriormente, ao teste Tukey a 5\% de probabilidade empregando-se o SAS software (SAS, v. 9.0) (SAS, 2002).

\section{Ensaio com feijão-de-porco}

Foram utilizadas plantas de feijão-de-porco (Canavalia ensiformis, Fabaceae) isentas de qualquer infecção por begomovírus, mediante seu cultivo em gaiolas teladas com organza $(1,40 \times 1,30 \times 1,20 \mathrm{~m}$, largura $\mathrm{x}$ profundidade $x$ altura), da semeadura nos vasos até o uso de suas folhas no ensaio.
Os tratamentos foram arranjados em esquema fatorial de 5 (quatro inseticidas (acefato, diafentiurom, pimetrozina e tiametoxam) nas concentrações listadas na Tabela 1 e água destilada como testemunha) x 2 [duas condições da mosca-branca, avirulífera (sem ToSRV) e virulífera (com ToSRV)] e dispostos no delineamento inteiramente casualizado, com 25 repetições.

Os inseticidas foram avaliados pela metodologia do resíduo seco da calda inseticida em disco foliar de feijão-de-porco, empregando água destilada como testemunha. Para tanto, utilizaram-se tubos de vidro com fundo chato (8 cm de altura $x 1,7 \mathrm{~cm}$ de diâmetro), contendo $1 \mathrm{~mL}$ de ágar a $3 \%(\mathrm{v} / \mathrm{v})$ depositado no fundo do recipiente. Os discos foliares $(1,65 \mathrm{~cm}$ de diâmetro) foram imersos nas caldas inseticidas por cinco segundos, destinados à secagem sobre toalha de papel com a face abaxial voltada para cima, e depositados com a face adaxial em contato com o ágar. Em seguida, os insetos (20 adultos não sexados) foram liberados nos recipientes acondicionados com a abertura voltada para baixo, de forma a reduzir possíveis interferências no hábito alimentar do inseto. Para evitar escapes, a abertura do recipiente foi vedada com organza. A mortalidade dos adultos foi avaliada após 24 e 48 h do início do ensaio.

Tendo em vista que a mortalidade dos insetos foi avaliada na mesma unidade amostral em dois períodos (24 e 48 h), empregou-se a análise de variância por medidas repetidas para evitar o problema de pseudo-repetição e da falta de homogeneidade das matrizes de variância/covariância entre as datas analisadas. Assim, os dados foram submetidos à análise de variância por medidas repetidas (PROC ANOVA com especificação Contrast) no esquema fatorial $5 \times 2$, tendo os momentos de avaliação da mortalidade como medidas repetidas na mesma unidade experimental, conforme sugerido por Von Ende (1993). A comparação entre médias dos tratamentos foi realizada dentro de cada momento de avaliação pelo teste Tukey, ao nível de 5\% de significância, empregando-se o SAS software (SAS, v. 9.0). A mortalidade de adultos de B. tabaci biótipo B em razão dos tratamentos foi corrigida 
pela respectiva testemunha, utilizando a fórmula de Schenneider-Orelli (Püntener, 1981).

\section{RESULTADOS E DISCUSSÃO}

A presença de TOSRV foi detectada pelo teste molecular em 100\% dos adultos coletados da população que se alimentou em plantas de tomateiro infectadas, enquanto nenhum inseto com begomovírus foi encontrado nas amostras da população que se alimentou em plantas sadias.

Não foi observado efeito da interação, entre a condição da mosca-branca (virulífera vs. avirulífera) e os inseticidas testados, nos ensaios com tomateiro $\left(\mathrm{F}_{5,60}=1,27 ; \mathrm{P}=0,2902\right)$ e com feijão-deporco $\left(\mathrm{F}_{3,192}=1,04 ; \mathrm{P}=0,3772\right)$.

Não houve diferença significativa na mortalidade de $B$. tabaci biótipo $\mathrm{B}$ em razão da condição dos adultos (virulíferos vs. avirulíferos) nos experimentos com plantas de tomateiro $\left(\mathrm{F}_{1,60}=\right.$
$1,61 ; \mathrm{P}=0,2094)$ e com discos foliares de feijão-de-porco $\left(\mathrm{F}_{1,192}=0,05 ; \mathrm{P}=\right.$ 0,8308), demonstrando que a aquisição prévia do ToSRV não teve influência na sobrevivência do inseto. Considerando apenas o fator condição de virulência, adultos de $B$. tabaci biótipo B avirulíferos e virulíferos em tomateiro apresentaram mortalidades médias de 27,39\% e 33,49\%, respectivamente (Figura 1A). Resultados semelhantes foram obtidos em disco foliar de feijão-de-porco, onde moscas-brancas avirulíferas e virulífe-

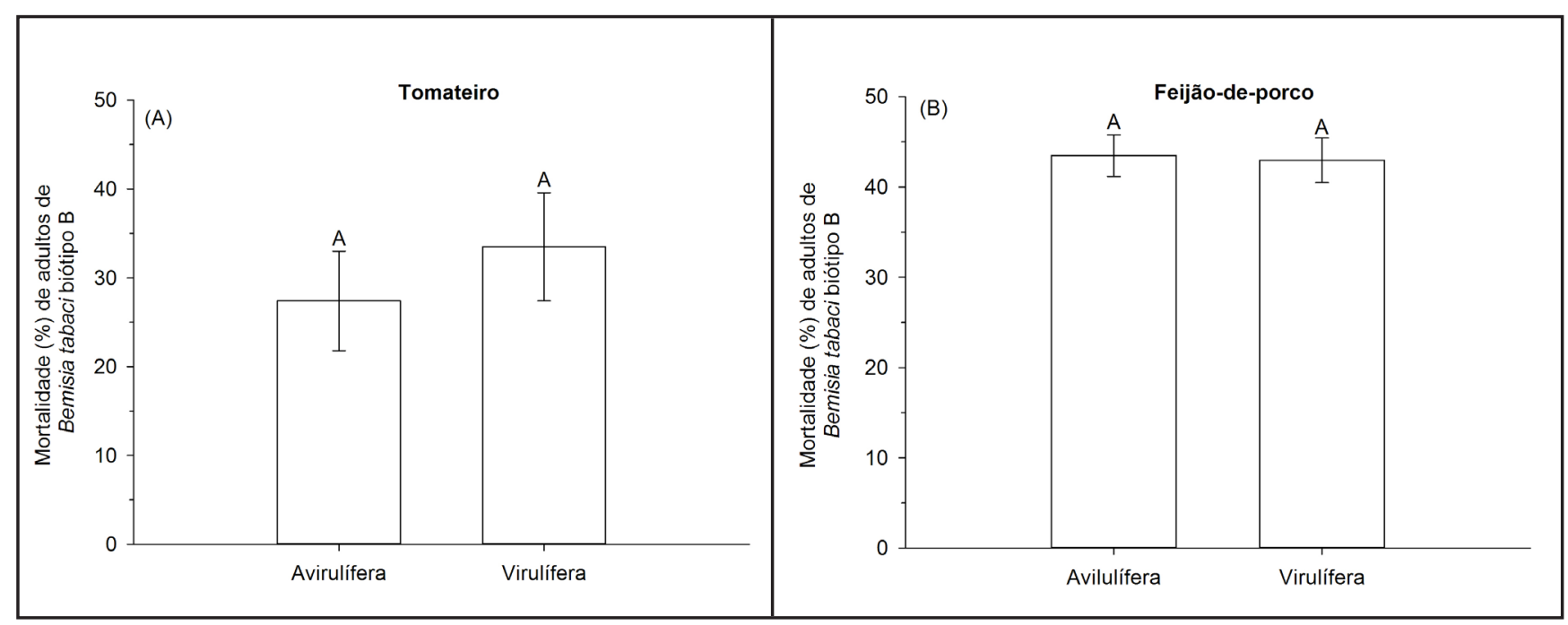

Figura 1. Mortalidade (\%) corrigida pela testemunha, de adultos de Bemisia tabaci (Gennadius) (Hemiptera: Aleyrodidae) biótipo B avirulíferos (sem aquisição prévia de Tomato severe rugose virus (ToSRV) e virulíferos (com aquisição prévia do ToSRV) em plantas de tomateiro (A) e de feijão-de-porco (B). Médias seguidas pela mesma letra, não diferem estatisticamente entre si pelo teste de Tukey a P $>0,05$ \{mortality ratio (\%), corrected by the control mortality, of non-viruliferous (without previous acquisition of ToSRV) and viruliferous (with previous acquisition of ToRSV) Bemisia tabaci (Gennadius) (Hemiptera: Aleyrodidae) adults biotype B in tomato plants (A) and Jack beans foliar discs (B). Means followed by the same letter are not significantly different by Tukey test at $\mathrm{p}=0.05\}$. Brasília, UnB e Embrapa Hortaliças, 2012/2013.

Tabela 1. Descrição das moléculas inseticidas registradas para o controle de Bemisia tabaci (Gennadius) (Hemiptera: Aleyrodidae) biótipo $\mathrm{B}$ em tomateiro que foram testadas nos bioensaios realizados \{description of the insecticides registered for Bemisia tabaci (Gennadius) (Hemiptera: Aleyrodidae) control in tomato crops that were tested in bioassays \}. Brasília, UnB e Embrapa Hortaliças, $2012 / 2013$.

\begin{tabular}{|c|c|c|c|c|c|c|}
\hline $\begin{array}{l}\text { Nome } \\
\text { Técnico }\end{array}$ & $\begin{array}{c}\text { Nome } \\
\text { Comercial }\end{array}$ & $\begin{array}{l}\text { Concentração } \\
\text { do ia }^{1} \text { no } \mathrm{PC}^{2}\end{array}$ & $\begin{array}{l}\text { Dose do } \\
\text { PC }\end{array}$ & $\begin{array}{l}\text { Volume de } \\
\text { calda }(\mathrm{L})\end{array}$ & Grupo químico & Modo de ação \\
\hline Acefato & Orthene $750 \mathrm{BR}$ & $750 \mathrm{~g} / \mathrm{kg}$ & $100 \mathrm{~g}$ & 100 & Organofosforado & $\begin{array}{l}\text { Inibidor da } \\
\text { acetilcolinesterase }\end{array}$ \\
\hline Clotianidina & Focus WP & $500 \mathrm{~g} / \mathrm{kg}$ & $20 \mathrm{~g}$ & 100 & Icneumonoideo & $\begin{array}{l}\text { Agonistas de receptores } \\
\text { nicotínicos da acetilcolina }\end{array}$ \\
\hline Diafenturom & Polo $500 \mathrm{SC}$ & $500 \mathrm{~g} / \mathrm{kg}$ & $800 \mathrm{~g}$ & 300 & Feniltiuréia & $\begin{array}{l}\text { Inibidor da ATP } \\
\text { sintetase mitocondrial }\end{array}$ \\
\hline Pimetrozina & Chess 500WG & $500 \mathrm{~g} / \mathrm{kg}$ & $40 \mathrm{~g}$ & 100 & Piridina Azometina & $\begin{array}{l}\text { Bloqueador seletivo de } \\
\text { alimentação }\end{array}$ \\
\hline Piriproxifem & Tiger $100 \mathrm{EC}$ & $100 \mathrm{~g} / \mathrm{L}$ & $75 \mathrm{~mL}$ & 100 & $\begin{array}{c}\text { Éter } \\
\text { piridiloxipropílico }\end{array}$ & $\begin{array}{l}\text { Mímico do hormônio } \\
\text { juvenil }\end{array}$ \\
\hline Tiametoxam & Actara $250 \mathrm{WG}$ & $250 \mathrm{~g} / \mathrm{kg}$ & $20 \mathrm{~g}$ & 100 & Neonicotinoide & $\begin{array}{l}\text { Agonistas de receptores } \\
\text { nicotínicos da acetilcolina }\end{array}$ \\
\hline
\end{tabular}

1i.a.= Ingrediente ativo (active ingredient); $2 \mathrm{PC}=$ Produto comercial (commercial product). 
ras apresentaram mortalidades médias de $43,47 \%$ e $42,96 \%$, respectivamente (Figura 1B).

$\mathrm{Na}$ prática, estes resultados indicam que em uma lavoura de tomateiro, adultos de $B$. tabaci biótipo B virulíferos (que tenham adquirido ToSRV) que se estabelecerem em plantas sadias não estarão mais ou menos sujeitos à ação dos inseticidas devido a sua condição.

Conforme preconizado por Czosnek \& Ghanim (2012), a resposta no fitness [capacidade de um organismo, em virtude do seu genótipo, competir com êxito e contribuir com seus genes para as gerações posteriores (Campuzano-Martínez et al., 2010)] da mosca-branca virulífera é variável de acordo com o vírus adquirido e com o biótipo do inseto estudado. Nesse sentido, a associação de $B$. tabaci biótipo B com o ToSRV pode ter resultado em uma associação que tenha sido neutra (sem custos ou benefícios fisiológicos) em termos de fitness para o vetor, fazendo com que a suscetibilidade de insetos virulíferos ao controle químico seja a mesma de insetos avirulíferos.

Neste trabalho houve diferença significativa na mortalidade de $B$. tabaci biótipo $\mathrm{B}$ entre os inseticidas testados em tomateiro $\left(\mathrm{F}_{5,60}=28,17 ; \mathrm{P}=0,0001\right)$. $\mathrm{O}$ inseticida diafentiurom foi o que proporcionou a maior mortalidade da mosca-branca $(87,68 \% \pm 4,96)$ infestando o tomateiro, $48 \mathrm{~h}$ após o tratamento das plantas (Figura 2), sendo que os demais produtos proporcionaram mortalidades muito baixas (variando de 43,95\% a $6,90 \%$ ), não apresentando eficiência de controle satisfatória sobre o inseto.

Resultados semelhantes foram obtidos no teste com discos foliares de feijão-de-porco $\left(\mathrm{F}_{3,192}=174,18\right.$; $\mathrm{P}<0,0001)$. Contudo, o desempenho dos ingredientes ativos mudou entre as duas avaliações de mortalidade (interação significativa inseticida versus tempo: $\left.\mathrm{F}_{3,192}=49,54 ; \mathrm{P}<0,0001\right)$. Após 24 horas de exposição dos insetos, o inseticida diafentiurom ocasionou a maior mortalidade $(79,77 \% \pm 4,78)$ e diferiu significativamente dos demais inseticidas (Figura 3A). Por outro lado, na avaliação após 48 h (Figura $3 \mathrm{~B}$ ), os inseticidas mais eficientes

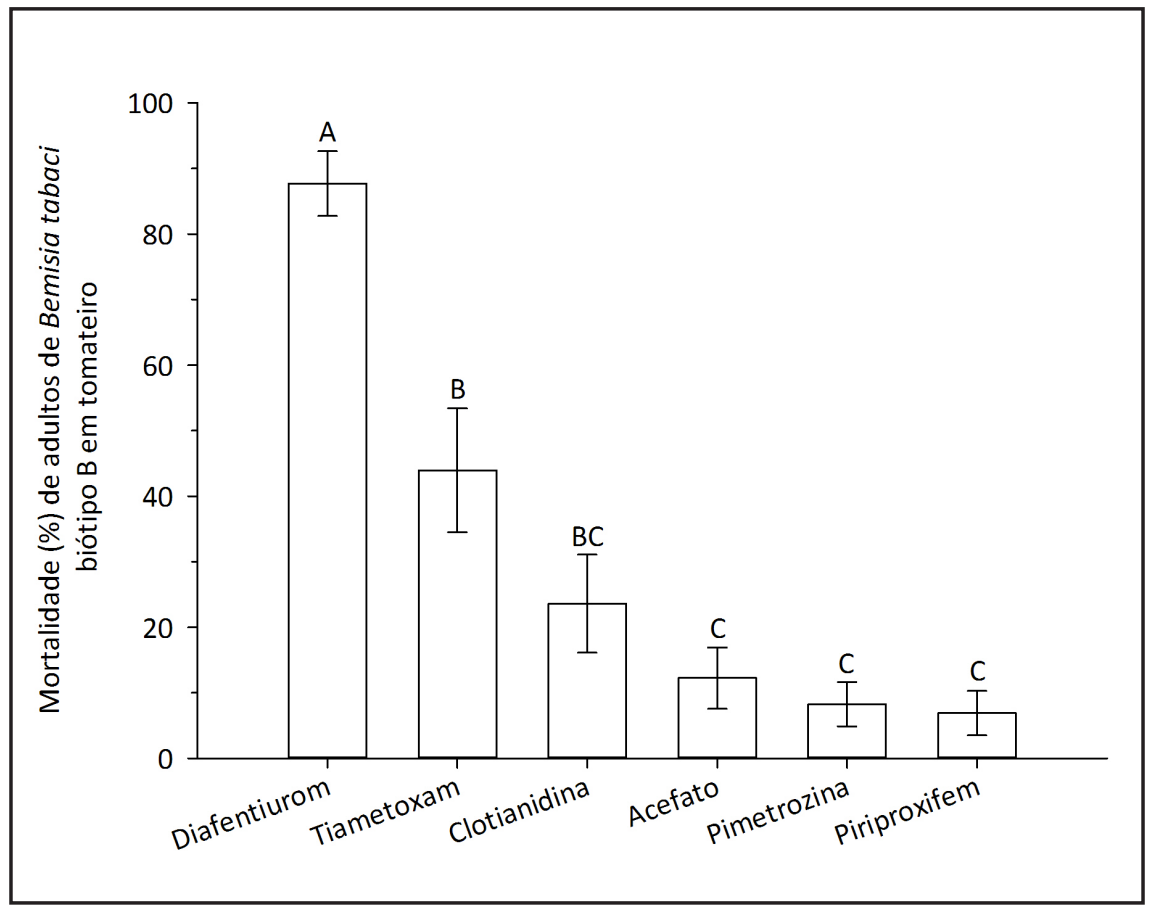

Figura 2. Mortalidade (\%) corrigida pela testemunha, de adultos de Bemisia tabaci (Gennadius) (Hemiptera: Aleyrodidae) biótipo B causada por seis inseticidas sintéticos depositados sobre plantas de tomateiro, após $48 \mathrm{~h}$ do início do ensaio. Médias seguidas pela mesma letra maiúscula, não diferem estatisticamente entre si pelo teste de Tukey a $\mathrm{P}>0,05$ \{mortality ratio (\%) corrected by control mortality of Bemisia tabaci (Gennadius) (Hemiptera: Aleyrodidae) biotype B adults caused by six synthetic insecticides residues laying on tomato plants, $48 \mathrm{~h}$ after the beginning of the bioassay. Means followed by the same letter are not significantly different by Tukey test at $\mathrm{p}=0.05\}$. Brasília, UnB e Embrapa Hortaliças, 2012/2013.

foram diafentiurom $(92,01 \% \pm 2,68)$ e tiametoxam $(86,39 \% \pm 2,74)$, os quais não diferiram entre si. O inseticida pimetrozina apresentou posição intermediária $(71,39 \% \pm 4,06)$, enquanto o acefato causou a menor mortalidade de adultos da mosca-branca $(12,09 \% \pm 1,74)$.

Embora tenha provocado as maiores mortalidades da mosca-branca, o diafentiurom deve ser usado com restrição no manejo de $B$. tabaci biótipo B por poder acarretar fitointoxicação (queima foliar) no tomateiro, algo que foi previamente verificado por Dias (2013).

A baixa mortalidade ocasionada pelo acefato está de acordo com a observada por outros autores que verificaram que este inseticida causou mortalidade insatisfatória de B. tabaci (Bacci et al., 2007). Há relatos de resistência de $B$. tabaci a inseticidas pertencentes ao grupo dos organofosforados (Alon et al., 2008). Portanto, a baixa mortalidade de B. tabaci biótipo B associada ao acefato, pertencente ao grupos dos organofosforados (Tabela 1), pode estar relacionada à evolução de resistência da praga ao modo de ação dessa molécula inseticida. Este resultado é alarmante tendo em vista que o acefato ainda é um dos inseticidas mais utilizados no controle da mosca-branca e é capaz de ocasionar reconhecidos efeitos deletérios sobre organismos não-alvo, sem, contudo, proporcionar controle efetivo do inseto.

O controle proporcionado pela pimetrozina nos ensaios com feijão-de-porco (cerca de $71 \%$ de mortalidade) não se refletiu nos ensaios com o tomateiro (cerca de $8 \%$ de mortalidade). Acredita-se que essas diferenças possam ser devidas ao fato de a área tratada e na qual os insetos permaneceram confinados, no caso do feijão-de-porco, ser bem inferior à do tomateiro, resultando em aumento de exposição do inseto ao produto. Estudos anteriores associam a pimetrozina, um composto inibidor da alimentação, à redução na taxa de transmissão do begomovírus Tomato yellow leaf curl virus 


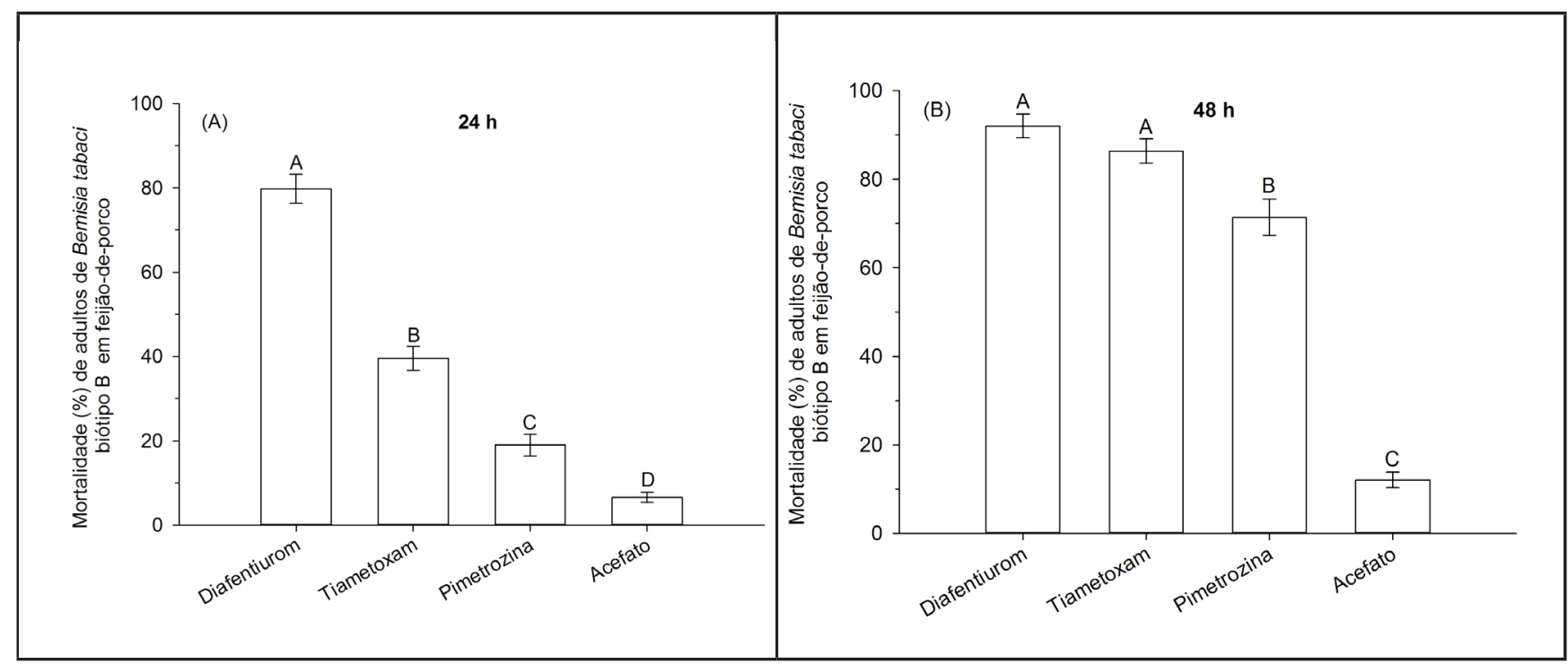

Figura 3. Mortalidade (\%) corrigida pela testemunha, após 24 h (A) e 48 h (B) da exposição de adultos de Bemisia tabaci (Gennadius) (Hemiptera: Aleyrodidae) biótipo B aos resíduos de quatro inseticidas sintéticos, depositados sobre discos foliares de feijão-de-porco. Médias seguidas pela mesma letra nas barras, não diferem estatisticamente entre si pelo teste de Tukey a $\mathrm{P}>0,05$ \{mortality ratio (\%), corrected by control mortality, $24 \mathrm{~h} \mathrm{(A)} \mathrm{and} 48 \mathrm{~h}$ (B) after exposing Bemisia tabaci (Gennadius) (Hemiptera: Aleyrodidae) biotype B adults to the residues of four synthetic insecticides laying on foliar discs of Jack beans. Means followed by the same letter are not different by Tukey test at $p=0.05\}$. Brasília, UnB e Embrapa Hortaliças, 2012/2013.

(TYLCV) para plântulas de tomateiro (Polston \& Sherwood, 2003). Todavia, resultados mais recentes demonstraram existir resistência cruzada a neonicotinoides e a pimetrozina em populações de B. tabaci (Nauen et al., 2013). Ensaios futuros devem prever a avaliação da pimetrozina no controle da mosca-branca sob condições diversas (casa de vegetação e campo) e sob diferente pressão de seleção da praga (densidade populacional), bem como investigar o risco de evolução da resistência nas populações da praga e o surgimento de sintomas de begomovirose após o surgimento de sintomas de begomovirose após o tratamento de plantas infestadas com moscas-brancas virulíferas.

O controle insatisfatório proporcionado pelo piriproxifem pode ser atribuído ao seu modo de ação específico, tendo em vista tratar-se de um produto mímico do hormônio juvenil (Tabela 1). Desta forma, a principal ação desse produto é verificada sobre estádios imaturos, apesar dele também exercer efeitos sobre adultos, contudo, sob maiores intervalos de tempo (de 4-8 dias) (Meola et al., 1993). Logo, ensaios futuros devem prever a avaliação da mortalidade de adultos sob maiores intervalos de tempo, bem como considerar a sua ação sobre o estádio ninfal da praga.

Em relação à clotianidina e ao tiametoxam, ambos pertencentes ao grupo dos neonicotinoides (Tabela 1), a baixa eficiência de controle pode ser devida à aquisição de resistência pelo inseto, tendo em vista que já existem relatos de resistência a esse grupo em populações de B. tabaci do Brasil (Silva et al., 2009). Todavia, em virtude da importância desse grupo para o manejo da mosca-branca, faz-se necessário o manejo das populações resistentes ou mesmo a inclusão de adjuvantes na calda inseticida, com vias à manutenção da efetividade e aumento da eficiência de controle obtida (Silva et al., 2009).

Na presente pesquisa, não se constatou diferença na mortalidade de adultos de $B$. tabaci biótipo B submetidos a diferentes inseticidas em razão da condição dos adultos virulíferos ou avirulíferos nos dois experimentos (plantas de tomateiro e discos foliares de feijão-de-porco). Assim, diante dos resultados obtidos, pode-se verificar a complexidade em controlar pragas de alto potencial causador de injúrias como a mosca-branca, tendo em vista que apenas um inseticida alcançou eficiência satisfatória. Essa situação demonstra a fragilidade da dependência exclusiva no controle químico para manejar o inseto, principalmente se considerarmos que as chances de evolução de resistência e transmissão integral à progênie são reais e intensificadas sob alta pressão de seleção. Desta forma, medidas de manejo da resistência e outras medidas que incorporem métodos de controle distintos devem ser implementadas.

\section{AGRADECIMENTOS}

À Coordenação de Aperfeiçoamento de Pessoal de Nível Superior (CAPES) pela concessão da bolsa de estudos ao primeiro autor. Ao Conselho Nacional de Desenvolvimento Científico e Tecnológico $(\mathrm{CNPq})$ pelo financiamento da proposta 'Manejo racional do complexo de pragas mosca-branca/begomovírus em tomateiro', Edital MCT/ CNPq/MEC/CAPES REPENSA e pela concessão da bolsa de produtividade em pesquisa aos demais autores do trabalho.

\section{REFERÊNCIAS}

ALON, M; ALON, F; NAUEN, R; MORIN, S. 2008. Organophosphates' resistance in the B-biotype of Bemisia tabaci (Hemiptera: Aleyrodidae) is associated with a point 
mutation in an ace1-type acetylcholinesterase and overexpression of carboxylesterase. Insect Biochemistry and Molecular Biology 38: 940-949.

BACCI, L; CRESPO, ALB; GALVAN, TL; PEREIRA, EJG; PICANÇO, MC; SILVA, GA; CHEDIAK, M. 2007.Toxicity of insecticides to the sweet potato whitefly (Hemiptera: Aleyrodidae) and its natural enemies. Pest Management Science 63: 699-706.

BARBOSA, JC; BARRETO, SS; INOUENAGATA, AK; REZENDE, JAM. 2011. Characterization and experimental host range of a Brazilian tomato isolate of Tomato severe rugose virus. Journal of Phytopathology 159: 644-646.

BRASIL. Ministério da Agricultura, Pecuária e Abastecimento (MAPA). 2012, 12 de agosto. Agrofit: sistema de agrotóxicos fitossanitários. Disponível em: http://agrofit.agricultura.gov. br/agrofit_cons/principal_agrofit_cons.

BYRNE, DN; BELLOWS JUNIOR, TS. 1991. Whitefly biology. Annual Review of Entomology 36: 431-457.

CAMPUZANO-MARTÍNEZ, A; RODRÍGUEZMACIEL, JC; LAGUNES-TEJEDA, A; LLANDERAL-CÁZARES, C; TERÁNVARGAS, AP; VERA-GRAZIANO, J; VAQUERA-HUERTA, H; SILVA-AGUAYO, G. 2010. Aptitud biológica de poblaciones de Bemisia tabaci (Gennadius) biotipo B (Hemiptera: Aleyrodidae) con diferente susceptibilidad al insecticida thiametoxam. Neotropical Entomology 39: 430-435.

CZOSNEK, H; GHANIM, M. 2012. Back to basics: are begomoviruses whitefly pathogens? Journal of Integrative Agriculture 11: 225-234.

DE BARRO, PJ; TRUEMAN, JWH; FROHLICH, DR. 2005. Bemisia argentifolii is a race of B. tabaci (Hemiptera: Aleyrodidae): the molecular genetic differentiation of $B$. tabaci populations around the world. Bulletin of Entomological Research 95: 193-203.

DIAS, AM. 2013. Manejo de mosca-branca com e sem begomovírus em plantas de tomate tratadas com inseticidas. Brasília: UnB. 21p. (Trabalho de conclusão de curso).

DINSDALE, A; COOK, L; RIGINOS, C; BUCKLEY, YM; DE BARRO, P. 2010. Refined Global analysis of Bemisia tabaci (Hemiptera: Sternorrhyncha: Aleyrodoidea: Aleyrodidae) mitochondrial cytochrome oxidase 1 to identify species level genetic boundaries. Annals of the Entomological Society of America 103: 196-208.

DOYLE, JJ; DOYLE, JL. 1987. A rapid DNA isolation procedure for small quantities of fresh leaf tissue. Phytochemical Bulletin 19:11-15.

FROHLICH, DR; TORRES-JEREZ, I; BEDFORD, ID; MARKHAM, PG; BROWN,
JK. 1999. A phylogeographical analysis of the Bemisia tabaci species complex based on mitochondrial DNA markers. Molecular Ecology 8: 1683-1691.

GIORDANO, LB; FONSECA, MEN; SILVA, JBC; INOUE-NAGATA, AK; BOITEUX, LS. 2005. Efeito da infecção precoce por Begomovirus com genoma bipartido em características de frutos de tomate industrial. Horticultura Brasileira 23: 815-818.

GORMAN, K; SLATER, R; BLANDE, JD; CLARKE, A; WREN, J; MCCAFFERY, A; DENHOLM, I. 2010. Cross-resistance relationships between neonicotinoids and pymetrozine in Bemisia tabaci (Hemiptera: Aleyrodidae). Pest Management Science 66: 1186-1190.

IBGE. 2013, 16 de novembro. Levantamento sistemático da produção agrícola. Disponível em: http://www.ibge.gov.br/home/estatistica/ indicadores/agropecuaria/lspa/lspa_201309. pdf

INOUE-NAGATA, AK; ALBUQUERQUE, LC; ROCHA, WB; NAGATA, T. 2004. A simple method for cloning the complete begomovirus genome using the bacteriophage $\varphi 29$ DNA polymerase. Journal of Virological Methods 116: 209-2011.

JIU, M; ZHOU, XP; TONG, L; XU, J; YANG, X; WAN, FH; LIU, SS. 2007. Vector-virus mutualism accelerates population increase of an invasive whitefly. Plos One 2: 182.

LIU, J; ZHAO, H; JIANG, K; ZHOU, XP; LIU, SS.2009. Differential indirect effects of two plant viruses on an invasive and an indigenous whitefly vector: implications for competitive displacement. Annals of Applied Biology 155: 439-448.

MA, W; LI, X; DENNEHY, TJ; LEI, C; WANG, M; DEGAIN, BA; NICHOLS, RL. 2010. Pyriproxyfen resistance of Bemisia tabaci (Homoptera: Aleyrodidae) biotype B: metabolic mechanism. Journal of Economic Entomology 103: 159-165.

MALUTA, NPK; GARZO, E; MORENO, A; LOPES, JRS; FERERES, A. 2014. Tomato yellow leaf curl virus benefits population growth of the Q biotype of Bemisia tabaci (Gennadius) (Hemiptera: Aleyrodidae). Neotropical Entomology 43: 385-392.

MCKENZIE, CL. 2002. Effect of Tomato mottle virus (ToMoV) on Bemisia tabaci biotype $\mathrm{B}$ (Homoptera: Aleyrodidae) oviposition and adult survivorship on healthy tomato. Florida Entomologist 85: 367-368.

MEOLA, R; READY, S; MEOLA, S. 1993. Physiological effects of the juvenoid pyriproxyfen on adults, eggs and larvae of the cat flea. In: WILDEY, KB; ROBINSON, WH. (eds). Proceedings of the first international conference on urban pests. England:
Cambridge. p.221-228.

MOREIRA, GR; SILVA, DJH; PICANÇO, MC; PETERNELLI, A; CALIMAN, FRB. 2005. Divergência genética entre acessos de tomateiro infestados por diferentes populações da traça-do-tomateiro. Horticultura Brasileira 23: 893-898.

NAUEN, R; VONTAS, J; KAUSSMANN, M; WÖLFEL, K. 2013. Pymetrozine is hydroxylated by CYP6CM1, a cytochrome P450 conferring neonicotinoid resistance in Bemisia tabaci. Pest Management Science 69: 457-461.

NIKAN, J; FENTON, B; BARKER, H. 2013. Differences in the life parameters related to population increase of some major genotypes of Scottish Myzus persicae, the main vector of Potato leafroll virus. Iranian Journal of Plant Pathology 48: 155-160.

POLSTON, JE; SHERWOOD, T. 2003. Pymetrozine interferes with transmission of Tomato leaf curl virus by whitefly Bemisia tabaci. Phytoparasitica 31: 490-498.

PÜNTENER, W. 1981. Manual for field trials in plant protection. Basel: Ciba-Geigi Limited. 271p.

ROJAS, MR; GILBERTSON, RL; RUSSEL, DR; MAXWELL, DP. 1993. Use of degenerate primers in the polymerase chain reaction to detect whitefly-transmited geminiviruses. Plant Disease 77: 340-347.

RUBINSTEIN, G; CZOSNEK, H. 1997. Long-term association of Tomato yellow leaf curl virus (TYLCV) with its whitefly vector Bemisia tabaci: effect on the insect transmission capacity, longevity and fecundity. Journal of General Virology 78: 2683-2689.

SANTOS, CDG; ÁVILA, AC; RESENDE, RO. 2003. Estudo da interação de um begomovírus isolado de tomateiro com a mosca branca. Fitopatologia Brasileira 28: 664-673.

SAS. 2002. The SAS system. Version 9.00. Cary: SAS Institute.

SHADMANY, M; OMAR, D; MUHAMAD, R. 2014. Biotype and insecticide resistance status of Bemisia tabaci populations from Peninsular Malaysia. Journal of Applied Entomology. Disponível em: http://dx.doi.org/10.1111/ jen.12131. Acessado em 07 de janeiro de 2015.

SILVA, LD; OMOTO, C; BLEICHER, E; DOURADO, PM. 2009. Monitoramento da suscetibilidade a inseticidas em populações de Bemisia tabaci (Gennadius) (Hemiptera: Aleyrodidae) no Brasil. Neotropical Entomology 38: 116-125.

Von ENDE, CN. 1993. Repeated-measures analysis: growth and other time-dependent measures. In: SCHEINER, S; GUREVITCH, J. (eds). Design and analysis of ecological experiments. New York: Chapman \& Halland. p. 113-137. 